\title{
Consuming sustainable seafood: guidelines, recommendations and realities
}

\author{
Anna K Farmery ${ }^{1, *}$, Gabrielle $\mathrm{O}^{\prime}$ Kane $^{2}$, Alexandra McManus ${ }^{3}$ and Bridget S Green ${ }^{4}$ \\ ${ }^{1}$ Institute for Marine and Antarctic Studies, University of Tasmania, Hobart, TAS 7001, Australia: ${ }^{2}$ Health Research \\ Institute, University of Canberra, Canberra, ACT, Australia: ${ }^{3}$ Faculty of Health Sciences, Curtin University, Perth, \\ WA, Australia: ${ }^{4}$ Institute for Marine and Antarctic Studies, University of Tasmania, Hobart, TAS, Australia
}

Submitted 21 June 2017: Final revision received 17 0ctober 2017: Accepted 27 November 2017: First published online 21 January 2018

\begin{abstract}
Objective: Encouraging people to eat more seafood can offer a direct, costeffective way of improving overall health outcomes. However, dietary recommendations to increase seafood consumption have been criticised following concern over the capacity of the seafood industry to meet increased demand, while maintaining sustainable fish stocks. The current research sought to investigate Australian accredited practising dietitians' (APD) and public health nutritionists' (PHN) views on seafood sustainability and their dietary recommendations, to identify ways to better align nutrition and sustainability goals.

Design: A self-administered online questionnaire exploring seafood consumption advice, perceptions of seafood sustainability and information sources of APD and PHN. Qualitative and quantitative data were collected via open and closed questions. Quantitative data were analysed with $\chi^{2}$ tests and reported using descriptive statistics. Content analysis was used for qualitative data.

Setting: Australia.

Subjects: APD and PHN were targeted to participate; the sample includes respondents from urban and regional areas throughout Australia.

Results: Results indicate confusion around the concept of seafood sustainability and where to obtain information, which may limit health professionals' ability to recommend the best types of seafood to maximise health and sustainability outcomes. Respondents demonstrated limited understanding of seafood sustainability, with $7 \cdot 5 \%(n$ 6/80) satisfied with their level of understanding.

Conclusions: Nutrition and sustainability goals can be better aligned by increasing awareness on seafood that is healthy and sustainable. For health professionals to confidently make recommendations, or identify trade-offs, more evidence-based information needs to be made accessible through forums such as dietetic organisations, industry groups and nutrition programmes.
\end{abstract}

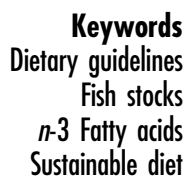

The consumption of seafood for health benefits is widely recommended in international dietary guidelines ${ }^{(1)}$. This is largely because it is the major source of the essential longchain PUFA, EPA and $\mathrm{DHA}^{(2)}$, commonly referred to as marine $n-3$ fatty acids. Humans can biosynthesise only small amounts of long-chain PUFA ${ }^{(3)}$, therefore foods rich in these fatty acids must be included in a healthy diet. Adequate ingestion of long-chain PUFA is linked to a range of health benefits including brain growth, visual development and protection from heart disease ${ }^{(4,5)}$. Seafood is the most readily available source of dietary long-chain PUFA. It is also an important source of essential micronutrients - vitamins A, B and $\mathrm{D}$ and minerals ( $\mathrm{Ca}, \mathrm{P}$, iodine, $\mathrm{Zn}, \mathrm{Fe}$ and $\mathrm{Se}$ ) - especially the many small fish species that are consumed whole (with bones, heads and viscera) ${ }^{(6)}$.
Consumers are aware of the health benefits of seafood ${ }^{(7)}$ and consumption has increased over time ${ }^{(8)}$, yet seafood consumption rates are generally lower than the amount recommended for positive health outcomes in national dietary guidelines ${ }^{(9-11)}$. There are many reasons why consumers may not be meeting the guidelines, including perceptions that seafood is expensive and is difficult to cook correctly, knowing if seafood is fresh and the possibility of ingesting seafood bones ${ }^{(7)}$. Encouraging higher consumption of seafood can offer a direct, effective, low-cost way of improving overall health outcomes ${ }^{(12)}$. The supply of seafood, including fish, crustaceans and molluscs, from wild-capture fisheries and aquaculture reached a record high of $20 \mathrm{~kg} /$ person in $2014^{(8)}$; however, dietary recommendations to increase seafood consumption have been criticised due to 
concerns over the capacity of the seafood industry to meet increased demand ${ }^{(13,14)}$. Broad concern over pressure on wild fish stocks ${ }^{(13,15-17)}$ and impacts from aquaculture ${ }^{(18)}$ has fuelled claims that seafood consumption in general may not be sustainable and that alternative sources of $n-3$ fatty acids should be sought ${ }^{(14)}$. However, actively recommending seafood that is sourced from sustainable sources could potentially alleviate the perceived conflicts between sustainability and health that stem from dietary recommendations for seafood intake ${ }^{(16,19-23)}$.

\section{Aligning bealth and sustainability guidelines}

Food-based dietary guidelines have been established in more than 100 countries $^{(24)}$ to provide policy makers, health practitioners and educators with evidence-based guidance on healthy foods, portion sizes and eating patterns that are tailored to the cultural and nutritional needs of individual countries. The aim of their publication in developed countries, such as Australia, is to promote health and well-being and reduce the risk of diet-related conditions and preventable chronic disease ${ }^{(1)}$. Given the links between food systems, human health and the environment, several countries have also considered food sustainability issues within their national dietary guidelines ${ }^{(25-29)}$, while others have drawn up guidelines for a sustainable $\operatorname{diet}^{(30,31)}$. The inclusion of information on sustainable seafood within the guidelines, as well as the literature on sustainable diets ${ }^{(32)}$, is limited and incomplete. In the 2013 Australian Dietary Guidelines, a recommendation to increase fish intake by $40 \%$ is premised by 'The extent to which Australian fish populations are sufficient to meet the guideline advice needs consideration' $^{\text {(1) }}$. No further information was provided on how best to consider this issue, or the fact that $70 \%$ of seafood consumed in Australia is imported ${ }^{(33)}$. Additional information on food, nutrition and environmental sustainability was requested in the latest revision of the Australian Dietary Guidelines; however, it was not included due to perceived limitations to the body of evidence about impacts, particularly the sometimes-conflicting considerations $^{(34)}$. A question therefore remains over how dietary advice to increase the intake of seafood can be coupled with current advice on seafood sustainability.

\section{Improving messages around seafood consumption}

Barriers to adherence to recommendations within dietary guidelines have been reported widely in relation to different populations and food groups ${ }^{(35-37)}$. Nevertheless, they provide an important source of evidence-based information for health professionals and educators and influence national food and nutrition programmes ${ }^{(1,38)}$. Nutrition advice from health professionals, in turn, can induce multiple dietary changes based on projected health outcomes ${ }^{(39)}$. Combining evidence-based dietary guidelines with information on food sustainability can provide an important resource for health professionals to educate clients, communities and populations about sourcing seafood - and other food groups - that are the most nutritious and, at the same time, sustainable food choices. Public health nutritionists (PHN) and accredited practising dietitians (APD) have the potential to play a key role in delivering messages to facilitate the behavioural change required to ensure that food choices are both healthy and sustainable $\mathrm{e}^{(40,41)}$.

Australia provides an ideal case study to examine the relationship between dietary advice on consuming seafood for good health and sustainability. Australia has recently reviewed its dietary guidelines and has a well-educated and established Nutrition and Dietetic workforce employed in hospitals, primary care and public health, yet seafood consumption remains lower than recommended ${ }^{(1)}$. Seafood consumption and seafood sustainability in Australia are also contested spaces. Advice on sustainable seafood can be conflicting and there has been criticism over the decision not to include guidance on sustainable diets or sustainable foods in the reviewed dietary guidelines in $2013^{(42,43)}$.

The current research sought to investigate the understanding of APD and PHN on seafood sustainability issues and their recommendations to clients regarding seafood consumption, to identify ways in which nutrition and sustainability goals can be better aligned. Specifically, we used Australia as a case study to examine: (i) seafood consumption advice given by APD and PHN; (ii) how concepts of seafood sustainability are perceived and interpreted by APD and PHN; (iii) how current recommendations and perceptions align with assessments of seafood sustainability; and (iv) the role of national dietary guidelines and the need for information to inform dietary advice on seafood consumption.

\section{Methods}

\section{Study subjects and survey implementation}

We targeted APD and PHN to participate in our survey as they are two key health professional groups nominated as intended users of the Australian Dietary Guidelines ${ }^{(1)}$. The survey was conducted as a self-administered online questionnaire using Qualtrics software, version 2015, during October and November 2016. A link to the survey was distributed through the Dietitians Association of Australia (DAA) and the Food and Nutrition Special Interest Group of the Public Health Association of Australia (PHAA; 6181 and 255 members, respectively) via email.

\section{Questionnaire development}

The questionnaire included a range of question types including yes/no option, multiple choice, open-ended, Likert scale and box tick. The questionnaire consisted of three components. The first investigated respondents' recommendations and advice given to clients regarding eating seafood, in relation to health and sustainability, using statements drawn from existing recommendations for healthy and 
sustainable diets ${ }^{(1,2,41-48)}$. The 'types' of seafood included in the survey were drawn from current consumption trends ${ }^{(49,50)}$ and seafood recommended for health ${ }^{(1,44)}$ and sustainability (www.sustainableseafood.org.au; www.sustainable.table.org. au; www.goodfishbadfish.com.au; www.frdc.com.au). Common names of seafood, as well as processed products such as fish-oil capsules, were listed as 'types' of seafood. An option was provided for respondents to record 'other types', recognising that seafood constitutes a diverse range of species, capture and production methods, and product types.

The second component investigated the sources of information and resources used to inform the advice given to clients regarding fish consumption for health benefits, $n-3$ content and sustainability of fish stocks. Multiplechoice questions listing different common sources of information were used for this component. The third and final component on subjective knowledge of sustainability issues asked respondents what they understood as the most important issues around sustainability, through both box tick and open-ended questions, and to what extent they agreed with statements about seafood sustainability. Responses to open-ended questions were coded to determine frequency of responses to relevant themes. The statements on seafood sustainability were developed based on relevant literature ${ }^{(51-54)}$.

Demographic questions, including work location, education level and years of experience, were included to test their relationship with the questionnaire outcome variables (e.g. if APD and PHN were more likely to recommend seafood if they were located in urban areas with better access to fresh seafood).

\section{Seafood consumption and sustainability}

Information on the current consumption of seafood in Australia was sourced from the Fisheries Research Development and Corporation (FRDC) for Australian-produced seafood $^{(50)}$ and from Danenberg et al. ${ }^{(49)}$ for general seafood consumption. Australian Government fishery assessment reports $^{(53)}$ and the main seafood guides in Australia, the Australian Marine Conservation Society (AMCS) seafood guide and the Sustainable Table guide, were examined for assessments of seafood sustainability. Certification of fisheries or aquaculture production by the Aquaculture Stewardship Council (ASC) or the Marine Stewardship Council (MSC) was also noted (further details on the different sustainability assessments are available in the online supplementary material, 'Supplementary information' file).

\section{Statistical analyses}

Descriptive statistics were used to describe the raw data. Means and standard deviations are presented in table format where relevant. The $\chi^{2}$ method was used to test for significance between variables that were considered likely be influential and respondents making specific recommendations about seafood (yes/no response). Significance was taken as $P<0.05$. Variables included years of experience, satisfaction with level of understanding of seafood sustainability, education level and work location. Survey questions are available in the online supplementary material, 'Seafood dietary advice survey' file.

\section{Results}

\section{Survey respondents}

One hundred and thirteen (44\%) of the PHAA members and 2509 (41\%) of the DAA members who were emailed the link to the survey opened the email. A total of ninety-three respondents commenced the survey. Not all respondents answered each question. Reported percentages have been calculated using the number of responses to individual questions.

The sample includes respondents from urban and regional areas throughout Australia. Two respondents selected 'other', with one identifying they were based internationally. All respondents had tertiary-level education (Bachelor degree) with $67 \%$ ( $n$ 62) completing postgraduate studies, including Graduate Diplomas, Honours, Masters or $\mathrm{PhD}$ degrees. Respondents reported varied length of time in practice (Table 1) and constituted a representative sample of practising PHN and APD. The distribution of respondents across the

Table 1 Sociodemographic characteristics of survey respondents: accredited practising dietitians and public health nutritionists ( $n$ 93) responding to a self-administered online questionnaire about seafood consumption advice, perceptions of seafood sustainability and information sources, Australia, October-November 2016

\begin{tabular}{lrr}
\hline & $n$ & $\%$ \\
\hline State & & \\
ACT & 5 & 5 \\
NSW & 26 & 28 \\
NT & 3 & 3 \\
Other & 2 & 2 \\
QLD & 18 & 19 \\
SA & 4 & 4 \\
TAS & 4 & 4 \\
VIC & 28 & 30 \\
WA & 3 & 3 \\
Remoteness* & & \\
Major cities & 60 & 71 \\
Inner regional & 14 & 16 \\
Outer regional & 9 & 10 \\
Very remote & 1 & 1 \\
Remote & 1 & 1 \\
Years of experience & & \\
0-5 & 35 & 38 \\
6-10 & 26 & 28 \\
11-15 & 12 & 13 \\
16 or more & 20 & 22 \\
Highest educational qualification & & \\
Undergraduate degree & 30 & 33 \\
Postgraduate award & 62 & 67 \\
Member of DAA FEIG & & 29 \\
Yes & 29 & 69 \\
No & 64 & \\
\hline & &
\end{tabular}

ACT, Australian Capital Territory; NSW, New South Wales; NT, Northern Territory; QLD, Queensland; SA, South Australia; TAS, Tasmania; VIC, Victoria; SA, South Australia; DAA FEIG, Dietitians Association of Australia's Food and Environment Interest Group.

${ }^{*}$ Calculated using http://www.pocog.org.au/aria/default.aspx 
States and Territories reflected the total membership distribution $^{(55)}$, with more respondents from the most populous regions of Australia. Given the limited number of respondents, the results described below provide a snapshot, rather than true representation, of the views of Australian PHN and APD.

\section{Current advice around seafood consumption}

Almost all respondents (98\%, $n$ 91) answered positively (yes/no response option) that they recommended eating seafood for health benefits. When asked for further detail, $90 \%$ ( $n$ 81) of these respondents indicated (via tick box) that they recommended consuming seafood as part of a healthy diet, while 70\% ( $n$ 60) recommended seafood for specific health benefits. Forty per cent $(n$ 36) of these respondents recommended eating seafood in combination with low-fat meats and $30 \%$ ( $n$ 27) recommended replacing other protein foods with seafood. Over half (57\%, $n$ 51) responded that they endorsed eating the amount of seafood recommended in the Australian Dietary Guidelines.

The majority of respondents $(79 \%, n$ 68) recommended specific types of seafood for health from a yes/no option. Respondents selected seafood types listed as common names or product (e.g. fish-oil capsules or liquid). Respondents were also given an option to describe other types; answers included common names not listed, as well as the sources of seafood, such as 'wild-capture', and seafood properties, such as 'oily fish'. In comparison, 35\% ( $n$ 21) made recommendations on specific seafood types, including specific species, common names and fishing methods, based on sustainability.

No significant difference was found regarding advice recommending particular species of seafood and respondents' years of experience (0-5, 6-10, 11-15, 16 years or more; $\left.\chi^{2}=4 \cdot 74, \quad \mathrm{df}=3, \quad P=0 \cdot 19\right)$. Those with undergraduate qualifications accounted for $40 \%$ of respondents to the question on recommending seafood based on sustainability. They were equally divided (50\%) as to whether they recommended particular species or not. However, almost $70 \%$ of respondents with postgraduate qualifications, predominantly Masters degrees, did not recommend species based on sustainability. There were no significant differences regarding advice recommending particular species of seafood according to education level (Bachelor, Graduate Diploma, Honours, Masters, $\mathrm{PhD} ; \chi^{2}=5 \cdot 9$, $\mathrm{df}=4$, $P=0 \cdot 21$ ). Forty per cent of respondents based in major cities recommended seafood based on sustainability, with $24 \%$ and $14 \%$ of inner regional and outer regional respondents, respectively. There were no significant differences regarding advice recommending particular species of seafood and respondents' location (major city, inner regional, outer regional, remote; $\chi^{2}=0.83, \mathrm{df}=3$, $P=0 \cdot 84)$. Very few respondents were based in remote or very remote areas and a larger sample of these respondents would be required to determine the relationship between remoteness and making specific recommendations.

\section{Concepts and perceptions of sustainability and seafood}

The most important issues around seafood sustainability related primarily to wild-capture fishing (Table 2). Overfishing was identified as an important issue by $62 \%$ ( $n$ 50) of respondents, as well as by $50 \%$ ( $n$ 37) in the openended questions. Other issues of concern included bycatch, the ability of fishing to continue into the future, habitat damage and the method of fishing. Content analysis of open-ended responses on what sustainability meant to respondents also revealed that the capacity of fishing to continue into the future $(31 \%, n$ 20) was important, as were impacts on the environment or ecosystem ( $43 \%, n$ 28). Habitat damage $(5 \%, n 3)$, carbon footprint $(3 \%, n 2)$, maintaining the quality of products $(3 \%, n 2)$, no bycatch $(3 \%, n 2)$, low food miles $(3 \%, n 2)$ and appropriate use (i.e. not for pet food; $3 \%, n 2$ ) were identified by a small number of respondents.

Few respondents either strongly agreed or strongly disagreed with statements on aspects of sustainability of fishing and aquaculture, with most responding as 'Neither agree nor disagree'. Two-thirds of respondents agreed that Australian fisheries were well-managed (63\%, $n$ 50). It was notable that the same proportion of respondents agreed that most fish stocks were overfished (63\%, $n$ 50). Further, $41 \%$ ( $n$ 24) agreed with the statement that Australian aquaculture was unsustainable. These neutral and seemingly contradictory responses appear to reflect a degree of confusion and uncertainty around seafood sustainability (Table 3), although we acknowledge that neutrality could also indicate ambivalence or be a function of the way the question was constructed. Qualitative responses from open-ended questions offer some insight into the confusion and uncertainty of respondents around sustainability. The following two responses provide indicative examples: 'I'm not comfortable with recommending $3+$ serves per week of

Table 2 Important concepts around seafood sustainability identified by respondents: accredited practising dietitians and public health nutritionists ( $n$ 93) responding to a self-administered online questionnaire about seafood consumption advice, perceptions of seafood sustainability and information sources, Australia, OctoberNovember 2016

Sustainable seafood concepts (in order of importance)

Species not overfished

Bycatch (other fish and animals such as turtles, mammals, birds caught in nets)

Minimise environmental/ecosystem impacts

Fishing can continue into the future

Does not damage physical environment (habitat)

Low carbon footprint of the product

Maintain quality products

Low food miles

Appropriate use (i.e. not for pet food)

Responses derived from a list in which respondents were asked to select the most important issues in terms of seafood sustainability (Q15), as well as an open-ended question on what sustainability in relation to seafood means to them (Q17). See online supplementary material, 'Seafood dietary advice survey' file, for original questions. 
Table 3 Perceptions of sustainability of seafood among accredited practising dietitians and public health nutritionists $(n 80)$ responding to a self-administered online questionnaire about seafood consumption advice, perceptions of seafood sustainability and information sources, Australia, October-November 2016

\begin{tabular}{|c|c|c|c|}
\hline To what extent do you agree with the following statements? & $\begin{array}{l}\text { Agree } \\
(\%)\end{array}$ & $\begin{array}{l}\text { Disagree } \\
(\%)\end{array}$ & $\begin{array}{l}\text { Neither agree } \\
\text { nor disagree (\%) }\end{array}$ \\
\hline Most fish stocks are overfished & 63 & 11 & 26 \\
\hline Australian fisheries are well-managed & 63 & 9 & 28 \\
\hline $\begin{array}{l}\text { Eating less common seafood species (e.g. mackerel) is more sustainable than eating } \\
\text { the most popular ones (e.g. snapper) }\end{array}$ & 45 & 10 & 45 \\
\hline Australian aquaculture is well-managed & 41 & 10 & 49 \\
\hline Seafood can be more sustainable than other animal proteins & 43 & 21 & 36 \\
\hline Aquaculture is unsustainable & 30 & 29 & 41 \\
\hline Only seafood from the AMCS seafood guide green list is sustainable & 18 & 11 & 71 \\
\hline Imported seafood comes from well-managed fisheries & 2 & 49 & 49 \\
\hline Imported seafood comes from well-managed aquaculture & 2 & 50 & 48 \\
\hline
\end{tabular}

AMCS, Australian Marine Conservation Society.

seafood given information around fish stocks collapsing' and 'I have been advised that even farmed fish is not sustainable, so feel guilty about recommending eating fish, yet feel obliged to do so'.

The words 'extinction' and 'dying out' were used by nine respondents in open-ended responses in reference to overfishing, indicating that some respondents associate overfishing with the complete removal of the species.

Australian seafood was recommended in preference to imports by most respondents (65\%, $n$ 53), although when asked about the difference between Australian and imported seafood, more than half of respondents answered that they were not aware of any differences in health $(58 \%$, $n 47)$ or sustainability $(51 \%, n 41)$. For those who were aware of differences between the sustainability of Australian and imported products, the regulation and fishing practices of Australian fisheries were perceived to be stronger than in other countries. Respondents were also aware of waterquality issues particularly in relation to imported prawns. Some respondents thought that imports were generally less sustainable than Australian products and 2\% agreed that imported seafood comes from well-managed aquaculture or fisheries.

Fewer than $10 \%$ of respondents were satisfied, as opposed to somewhat satisfied or not satisfied, with their level of understanding of seafood sustainability issues (seafood in general, 7.5\%, $n$ 6; Australian seafood, 10\%, $n 8$; imported seafood, $6 \cdot 3 \%, n 5$ ). Those who were satisfied with their level of understanding of sustainable seafood options were statistically more likely to recommend specific species than those who were not satisfied with their level of knowledge $\left(\chi^{2}=6.67, \quad \mathrm{df}=2, \quad P=0.035\right.$; Fig. 1).

While almost all respondents recommended seafood for health, over $60 \%(62 \%, n 51)$ expressed some concern over their recommendations. Within this group, the most highly rated concern was sustainability, followed by cost, access to high-quality products and food safety. Respondents who rated their level of concern as high represented all the experience groups. Comparing the level of concern

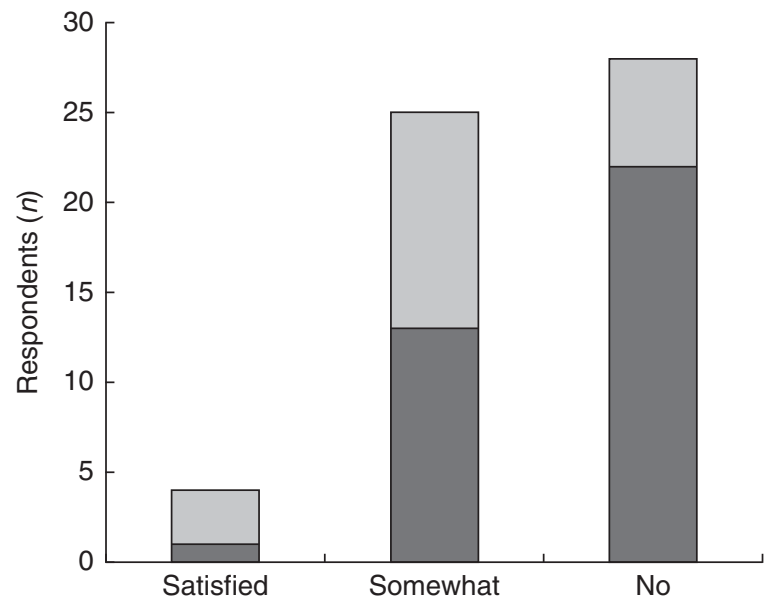

Fig. 1 Satisfaction with level of understanding of sustainability issues relating to general seafood, and whether they recommend specific types of seafood $(\square)$ or not $(\square)$ based on sustainability, among accredited practising dietitians and public health nutritionists ( $n$ 93) responding to a self-administered online questionnaire about seafood consumption advice, perceptions of seafood sustainability and information sources, Australia, October-November 2016

about fish sustainability between respondents who were members of DAA's Food and Environment Interest Group (FEIG) and those who were not, 95\% ( $n$ 19) of the members rated sustainability as a high concern, while $77 \%{ }^{(24)}$ of non-members had the same level of concern over sustainability. Of the eight respondents who reported they were satisfied with their level of understanding with seafood in general, five were members of the FEIG.

\section{Dietary guidelines and other sources used to inform dietary recommendations for seafood}

Dietary guidelines were the main source of information on seafood consumption used by the APD and PHN surveyed. Respondents also consulted with each other, as well as accessed resources such as the Heart Foundation Guidelines and academic papers for information on seafood consumption and $n-3$. The majority of respondents 
stated that there was not enough information available to provide advice on general seafood sustainability (65\%, $n 52)$ to clients, particularly in regard to imported seafood ( $86 \%, n$ 68), and academic journal papers and the AMCS seafood guide were used more commonly by respondents than the dietary guidelines for sustainability information. No respondent mentioned the comprehensive Status of Fish Stocks Reports as a source of sustainability information, although a number of respondents reported using information from the FRDC $(8 \%, n 6)$ or seafood industry materials $(12 \%, n 9)$.

Twenty-nine per cent ( $n$ 16) of respondents recommended the dietary guidelines as a source of information on sustainability for their clients. The same proportion of respondents also indicated that they do not recommend any type of information to clients on seafood sustainability. Further, for $66 \%$ ( $n$ 48) of respondents there was not enough information available about seafood sustainability for clients, particularly for imported seafood ( $71 \%, n 52)$. APD and PHN were largely unsure about their clients' level of concern about seafood sustainability, indicating that client demand was not a driver for health professionals to learn more about or make recommendations based on sustainability. Despite this result, $78 \%$ of respondents wanted more reliable information to be made available about sustainable seafood. Suggestions included evidencebased guidelines on specific types of seafood to recommend for both health and sustainability such as scorecards, a chapter in the dietary guidelines, or easily accessible materials such as brochures or fact sheets.

\section{Comparison of seafood types based on sustainability assessments}

\author{
Types of seafood recommended for health and \\ sustainability
}

Some of the types of seafood recommended for health matched those recommended based on sustainability (Table 4), including sardines, Atlantic salmon, tuna, mackerel and prawns. Of these species, tuna, salmon and prawns are among the most commonly eaten seafoods in Australia (Table 4). Barramundi was also recommended based on health and was one of the most commonly eaten species. Mackerel and sardines were not commonly eaten, despite being recommended for both health and sustainability. Supplements continue to be recommended for health benefits. 'Wild harvest' seafood was also recommended for sustainability by respondents in place of actual species names.

Of the top types recommended for health and sustainability - salmon, sardines, tuna, mackerel and barramundi (Table 4) - some Australian fisheries are assessed as sustainable by government fishery assessments, while others are not, including bigeye tuna (Eastern stock), yellowfin tuna (Western stock) and bluefin tuna ${ }^{(56,57)}$. The sustainability of imports of these seafood types is not always clear; for example, some tuna fisheries in the Western and Central Pacific Ocean are subject to overfishing and overcapacity ${ }^{(58)}$, while others from the same region have MSC certification. Atlantic salmon is not considered sustainable by the AMCS guide or by the

Table 4 Ranking of the top ten types of seafood recommended and consumed in Australia

\begin{tabular}{|c|c|c|c|c|}
\hline & \multicolumn{2}{|c|}{$\begin{array}{l}\text { Recommended by } \\
\text { APD and } \mathrm{PHN}^{*}\end{array}$} & \multicolumn{2}{|c|}{ Consumed in Australia } \\
\hline & Health & Sustainability & $\begin{array}{l}\text { Australian seafood } \\
\text { (based on volume) }^{(50)}\end{array}$ & $\begin{array}{l}\text { Australian and imported seafood } \\
\text { (based on occasions) }^{(49)}\end{array}$ \\
\hline Atlantic salmon & 1 & 2 & 1 & 4 \\
\hline Tuna & 3 & 5 & 4 & 1 \\
\hline Barramundi & 6 & 4 & 7 & 7 \\
\hline Prawns & 9 & 7 & 2 & 2 \\
\hline Sardines & 2 & 1 & & \\
\hline Mackerel & 4 & 10 & & \\
\hline Fish-oil capsules or liquid & 5 & & & \\
\hline Foods and drinks enriched with marine $n-3$ PUFA & 7 & & & \\
\hline Herring & 8 & & & \\
\hline Bream/blue eye/mussels & 9 & & & \\
\hline Smaller fish & & 3 & & \\
\hline Wild harvest & & 9 & & \\
\hline Whiting & & 6 & & \\
\hline Crab & & 8 & 6 & \\
\hline Mullet & & & 8 & \\
\hline Flathead & & & 9 & \\
\hline Oysters & & & 3 & 9 \\
\hline Shark & & & 5 & 6 \\
\hline Anchovies & & & & 10 \\
\hline Unsure of species (battered, crumbed, sushi, fish fingers) & & & & 3 \\
\hline
\end{tabular}

${ }^{*}$ Accredited practising dietitians (APD) and public health nutritionists (PHN) who responded $(n$ 80) to the self-administered online questionnaire about seafood consumption advice, perceptions of seafood sustainability and information sources, Australia, October-November 2016. 
Sustainable Table guide, although some farms have been certified by the ASC. The AMCS guide also gives the orange or red light to sardines, tuna and some stocks of mackerel, while the Sustainable Table guide gives the red light to bluefin tuna.

Prawns are commonly eaten, alongside tuna and salmon, and are also recommended for health and sustainability. Assessments of prawns vary within Australia, with some fisheries considered to be sustainable while others are subject to overfishing ${ }^{(57)}$ or considered unsustainable due to bycatch ${ }^{(59)}$. Imported prawns are given the red light by both seafood guides examined here ${ }^{(59,60)}$.

\section{Discussion}

Seafood is widely recommended for its many health benefits ${ }^{(1,48)}$; however, among the subset of APD and PHN who responded to our survey there was uncertainty around recommending seafood based on sustainability. The APD and PHN who participated in the current research expressed limited understanding around issues of seafood sustainability and reported a lack of satisfaction with their knowledge of the issues and where to obtain current information on sustainability. This knowledge gap may limit the ability of APD, PHN and other health professionals to recommend the best types of seafood to maximise health and sustainability outcomes. These health professionals are in a unique position to integrate and advance sustainable food system initiatives $^{(41)}$ and they need simpler sustainability advice in order to make sound recommendations on seafood. There is scope to improve and expand the recommendations being made to improve both sustainability and health outcomes.

\section{Concepts and perceptions of sustainability and seafood}

Previous studies have reported that recommendations to eat fish are viewed by health professionals as important to implement ${ }^{(61)}$ and almost all the health professionals in the present study recommended eating seafood to clients. However, respondents' uncertainty over whether seafood is or is not sustainable, combined with uncertainty over where to access reliable, evidence-based information, is likely limiting their capacity to make informed recommendations. Conflict, identified through the present study, in the advice and information available also hinders the health professional in advising consumers. Conflicts can arise from the fact that 'sustainability' is not an attribute of a particular process or product, but rather a set of personal values or a dynamic state in which biophysical processes are in equilibrium ${ }^{(62)}$. Organisations charged with providing information on seafood sustainability differ in the way they perceive or define 'sustainability', resulting in situations where a seafood product can be categorised as both sustainable and unsustainable, depending on the criteria used to define 'sustainable ${ }^{,(53)}$. These conflicting messages on seafood sustainability have also led to consumer confusion ${ }^{(21,63)}$. Conflicting messages, in combination with the lack of information about the sustainability of imported seafood, further complicate the issue, making it difficult to align health and sustainability goals.

The health professionals surveyed were generally not confident to make recommendations on what constitutes a sustainable seafood choice. Several expressed feelings of guilt around recommending seafood as they felt strongly that it should be recommended for health, yet had reservations based on the lack of information and conflicting messages around sustainability of the product. Some of these reservations may be overcome through improved understanding of fisheries terminology, including 'overfishing', 'fishery collapse' and 'extinction'. For example, there is a vast difference between a fish stock being assessed as overfished, which is a fishery management target and may require only moderate management responses (e.g. catch restrictions to stop, or reverse, declines), and fishing to the point of fishery collapse or to the point of species extinction ${ }^{(64)}$. Avoiding recommending seafood based on concerns over fishery collapse and species extinctions may therefore be over-cautious, particularly for seafood from countries with well-established fisheries management. A simpler language around fisheries terms that clearly describe the sustainability risks could avoid this issue.

An understanding of the often-complex issues relating to seafood sustainability is important for health professionals to be able to make informed recommendations on health and sustainability, as well as to build greater awareness of the potential trade-offs between these outcomes. More transparency in the evidence base used to develop dietary guidelines and sustainability information will help to clarify where a recommendation can be made to optimise health and sustainability, and where a judgement or compromise might be required. Despite the different interpretations and definitions of sustainability, there are some commonalities, including that species considered to be overfished are not assessed as sustainable.

\section{Alignment between sustainability assessments and bealth professionals' recommendations and perceptions}

A small number of seafood species were generally recommended by APD and PHN for health, and less for sustainability, despite hundreds of fish species available in Australia. Current sustainable seafood guides cover a limited range of species and typically have a regional focus, despite the global nature of the seafood market ${ }^{(63)}$. Approximately thirty types of seafood are given the green light in the AMCS guide and a limited number of species certified by the MSC or ASC are available in Australia. However, there is a much greater number of species that could potentially be recommended and consumed. There 
are over 4000 domestic finfish in Australia ${ }^{(65)}$, and over 600 domestic and imported species of seafood are considered commercially important in Australia. There is a risk that APD and PHN will, in the attempt to recommend sustainable choices, continue to choose a narrow range of seafood identifiable through ecolabels or guides, if information on a broader range of species is not easily accessible. To resolve this, sustainably fished species which require less resource use and have a lower impact on ecosystems and habitats could be identified and promoted over those that have a greater impact.

The top three commonly eaten seafood types in Australia (prawns, tuna, Atlantic salmon) are also among the top five most commonly eaten in the USA ${ }^{(66)}$ and are all recommended for their benefits to human health. The narrow focus on these particular types of seafood by health professionals and consumers overlooks the opportunity to eat a wider variety of sustainable seafood types. For example, sardines and mackerel are recommended for their health benefits, and assessed as sustainable, yet these seafood types are not commonly eaten across Australia, while a range of other species are neither commonly consumed nor recommended for consumption, despite being assessed as sustainable.

Seafood varies significantly in terms of environmental impacts as well as nutritional content. For example, barramundi and prawns farmed in Australia have the green light from the AMCS and are also good sources of $n$-3 fatty acids, although the amount is dependent on the feed used. Barramundi and prawns are also imported into Australia and the environmental impacts and nutritional content of these products are not as well understood. Wild barramundi is not considered to be overfished, although it is not recommended by AMCS due to interactions with bycatch and protected species ${ }^{(59)}$. Some species of wild-capture prawns are considered sustainable under both the government and independent assessments ${ }^{(51)}$. Recommendations for these species would therefore be improved if they articulated whether farmed or wild-caught; domestic or imported. Similarly, tuna is consistently identified in top recommendations for health and sustainability; however, bluefin stocks are overfished and the flesh is also low in $n-3$ fatty acids ${ }^{(67)}$. Gem fish is considered overfished in Australia and as a very good source of $n-3$ fatty acids, it has been recommended for consumption by the Heart Foundation ${ }^{(44)}$. The Heart Foundation has made efforts to delist known overfished species from its consumer resources and suggests interested individuals seek further information on sustainable choices.

Atlantic salmon is a good source of $n-3$ fatty acids, despite the content halving in the last decade ${ }^{(3)}$ as a result of reduced amounts of fish oil being used in feeds for farmed salmon ${ }^{(68)}$. The AMCS lists Atlantic salmon as unsustainable, based largely on the use of wild fish in the feed. This concern does not reflect recent changes to feed composition to greater use of terrestrial inputs and misses the opportunity to promote aquaculture products that have the best terrestrial resource-use efficiency and fewest environmental impacts.

\section{Alternatives for more sustainable options and aligning bealth and sustainability}

Several underutilised species of seafood have similar $n-3$ fatty acid content to Atlantic salmon, including mackerel, sardines, banded morwong, alfonsiono and whitebait ${ }^{(68)}$. Dietary advice encouraging people who regularly eat fish to consume as wide a variety as possible and experiment with less familiar species from underutilised stocks, such as coley, gurnard and mackerel ${ }^{(23)}$, has been trialled to shift fishing effort away from highly targeted stocks and towards currently underutilised species ${ }^{(69)}$. Consumption of underutilised species has also been promoted by celebrity chefs in the UK, where sales of these species in supermarkets have increased ${ }^{(70)}$.

Broadening the scope of species included in sustainability guides would help facilitate the shift towards eating a wider range of species, as well as making the full list of species assessed as sustainable by government available to APD, PHN and consumers. Limiting recommendations to a small number of species also creates a risk that improvements in the broader ecological effects of fishing and aquaculture are not being communicated to consumers and some species remain red on seafood guides despite being 'sustainable'. Improving traceability of seafood would also help determine the sustainability of imported products which make up the bulk of seafood consumed in Australia ${ }^{(71)}$.

Seafood guides predominantly focus on wild-capture species, despite the wide range of aquaculture fish, molluscs and crustaceans now available, and only a limited number of aquaculture types are promoted by health professionals, including the carnivorous Atlantic salmon. However, some aquaculture production does not require any feed, such as mussels and other bivalves, and these forms of aquaculture have a much lower environmental footprint ${ }^{(72)}$. They can also be a good source of $n-3$ fatty acids, although not as high as finfish such as salmon and some tunas ${ }^{(67)}$.

\section{Information gaps and role of the dietary guidelines in aligning sustainability with nutrition}

The Australian Dietary Guidelines were reported as the main source of information on seafood consumption. The National Health and Medical Research Council (NHMRC), who developed the guidelines, currently takes into consideration a number of issues that affect food choices, such as personal preferences, cultural backgrounds or philosophical choices such as vegetarian dietary patterns. The concept of 'health', like the concept of 'sustainability', is not static and is subject to varied interpretations and value judgements ${ }^{(73)}$. There have been calls to broaden 
the dietary guidelines to consider human health in the context of planetary health ${ }^{(42)}$ and many organisations have investigated broadening their consideration of health and sustainability. The Dietary Guidelines Advisory Committee in the USA recommended that sustainability be taken into account when determining the government's dietary advice ${ }^{(74)}$. However, this advice met with opposition $^{(38)}$ and sustainability was not included in the final 2015 Dietary Guidelines for Americans. Similarly, in Australia, the NHMRC removed the criteria of environmental sustainability from the 2013 dietary guidelines in response to criticism ${ }^{(34)}$ and instead a section on food, nutrition and environmental sustainability was included as an appendix ${ }^{(1)}$.

Several other countries have adopted a wider definition of health in their dietary guidelines, although the inclusion of seafood is limited. For example, the Health Council of the Netherlands ${ }^{(25)}$ undertook an assessment of the influence of diets on ecosystems which included marine biodiversity impacts from fishing, but aquaculture was not mentioned in the report. The Nordic Nutrition Recommendations 2012 ${ }^{(26)}$ included aquaculture, although incorrectly stated that 'wild fish in general are overexploited' $31.4 \%$ of stocks are currently assessed as overfished ${ }^{(8)}$ ) and questioned the sustainability of increasing seafood consumption. Interestingly, these nutrition recommendations proposed increasing seafood consumption as an option to reduce dairy consumption ${ }^{(33)}$. Advice related to fish consumption and sustainability in the Qatar Dietary Guidelines was described as confusing for consumers, who may find it difficult to ascertain which species are sustainable and which ones are unsustainable ${ }^{(29)}$.

The success of considering sustainability issues in dietary guidelines has, therefore, been limited. Alternatives for improving information and knowledge on the sustainability of seafood, and food more broadly, are also required. An example of different forums includes the dissemination of information through dietetic organisations. In Australia, a webinar on fish sustainability was held for the Food and Environment Group of the DAA to help inform members about the issues of seafood sustainability and $n-3$ fatty acids (personal communication, 2017). Recent publications by the American Dietetic Association (ADA) and the associated Hunger and Environmental Nutrition Group examined challenges related to the food system and provided valuable information for nutrition professionals ${ }^{(42)}$. However, concerns have been raised over the ADA's stance on sustainability given the organisation's extensive links and support from large industrial-based food companies ${ }^{(75,76)}$.

Another forum for aligning health and sustainability has been through dietetic internship programmes which integrate sustainability principles and practices through experiential learning ${ }^{(77)}$. This approach may be important as it can raise awareness of the issue at an early stage of health professionals' careers.

The health professionals involved in the current research were not driven by their clients' level of concern about seafood sustainability. Nevertheless, there is scope for more research on client needs and responses to information on sustainability, given that little is known about the impact of sustainability and ethical concerns on consumer decision making towards fish consumption ${ }^{(78)}$. The present study was small with a low response rate, but the distribution of respondents across the States and Territories reflected the total membership distribution ${ }^{(57)}$. Response rates to online surveys are typically lower than for on-paper surveys ${ }^{(79)}$ and future studies may benefit from more frequent email reminders to encourage more responses, as well as more direct targeting of APN and PHN. Caution must be exercised in interpreting the major findings of the current research. Respondents potentially had a prior interest in, or awareness of, seafood and sustainability which motivated them to complete the survey. Results may therefore reflect the views of those who are more likely to recommend seafood, and be aware of sustainability issues, than health professionals in general. Nevertheless, to the authors' knowledge, the present study is the first of any assessment of the knowledge of, and the recommendations given by, APD and PHN regarding seafood consumption for both health and environmental outcomes.

\section{Conclusion}

Health professionals have an important role to play in moving the food system towards more healthy and sustainable outcomes. Seafood is strongly embedded in recommendations around healthy eating, but as the present study shows, there is confusion among APD and PHN over the sustainability of products and uncertainty about where best to source information, which is very likely limiting the scope of potential seafood species recommendations. The study also showed that these health professionals were dissatisfied with their level of knowledge about sustainable seafood stocks and even expressed guilt about this shortfall in their knowledge base. There are a number of options available for health professionals to recommend both healthy and sustainable seafood types. However, for health professionals to confidently make these recommendations, or to identify where the trade-offs may lie, more evidence-based information needs to be made accessible, through forums such as dietetic organisations, industry groups and nutrition programmes. Evidence disseminated through these avenues could then be used in conjunction with dietary guidelines to improve the currency of health advice provided by health professionals for seafood as well as all food groups.

The sustainability of seafood may not be a high priority for health professionals, as indicated by the low response rate. Raising the profile of the sustainability of all food groups among health professionals is an important step for the future. 


\section{Acknowledgements}

Financial support: A.K.F. acknowledges funding support from the Sustainable Food Flagship of the Institute for the Study of Social Change as well as the Institute for Marine and Antarctic Science at the University Tasmania. The funders had no role in the design, analysis or writing of this article. Conflict of interest: None. Authorship: A.K.F., B.S.G. and G.O'K. were involved in the initial formulation of research questions. A.K.F., B.S.G., G.O'K. and A.M. were responsible for survey question content and design. A.K.F. was responsible for implementation and analysis of data. A.K.F. was responsible for the writing of the article with contributions from all authors. Ethics of buman subject participation: This study was conducted according to the guidelines laid down in the Declaration of Helsinki and all procedures involving human subjects were approved by the Tasmanian Social Science Human Research Ethics Committee (reference number H0016082). Informed consent was obtained from all subjects through the online survey.

\section{Supplementary material}

To view supplementary material for this article, please visit https://doi.org/10.1017/S1368980017003895

\section{References}

1. National Health and Medical Research Council (2013) Australian Dietary Guidelines. Canberra: NHMRC.

2. Lund EK (2013) Health benefits of seafood; is it just the fatty acids? Food Chem 140, 413-420.

3. Nichols PD, Glencross B, Petrie JR et al. (2014) Readily available sources of long-chain omega-3 oils: is farmed Australian seafood a better source of the good oil than wildcaught seafood? Nutrients 6, 1063-1079.

4. Lee JH, O'Keefe JH, Lavie CJ et al. (2009) Omega-3 fatty acids: cardiovascular benefits, sources and sustainability. Nat Rev Cardiol 6, 753-758.

5. Nichols PD, Petrie JR \& Singh SP (2010) Long-chain omega3 oils - an update on sustainable sources. Nutrients 2, 572-585.

6. High Level Panel of Experts (2014) Sustainable Fisheries and Aquaculture for Food Security and Nutrition. A Report by the High Level Panel of Experts on Food Security and Nutrition of the Committee on World Food Security. Rome: HPLE.

7. Christenson J, O'Kane G, Farmery AK et al. (2017) The barriers and drivers of seafood consumption in Australia: a literature review. Int J Consum Stud 41, 299-311.

8. Food and Agriculture Organization of the United Nations (2016) The State of World Fisheries and Aquaculture: Contributing to Food Security and Nutrition for All. Rome: FAO.

9. Hicks D, Pivarnik L \& McDermott R (2008) Consumer perceptions about seafood - an Internet survey. J Foodservice 19, 213-226.

10. McManus A, Hunt W, Storey J et al. (2014) Perceptions and preference for fresh seafood in an Australian context. Int $J$ Consum Stud 38, 146-152.

11. Meyer BJ \& Kolanu N (2011) Australian children are not consuming enough long-chain omega-3 polyunsaturated fatty acids for optimal health. Nutrition 27, 1136-1140.
12. McManus A, White J, Hunt W et al. (2011) Community Intervention to Increase Seafood Consumption (CIISC). Curtin University Report no. 16092011. Perth: Centre of Excellence for Science Seafood \& Health, Curtin Health Innovation Research Institute.

13. Greene J, Ashburn SM, Razzouk L et al. (2013) Fish oils, coronary heart disease, and the environment. Am J Public Health 103, 1568-1576.

14. Jenkins DJA, Sievenpiper JL, Pauly D et al. (2009) Are dietary recommendations for the use of fish oils sustainable? CMAJ 180, 633-637.

15. Brunner EJ, Jones PJS, Friel S et al. (2009) Fish, human health and marine ecosystem health: policies in collision. Int J Epidemiol 38, 93-100.

16. Clonan A, Holdsworth M, Swift JA et al. (2012) The dilemma of healthy eating and environmental sustainability: the case of fish. Public Health Nutr 15, 277-284.

17. Thurstan RH \& Roberts CM (2014) The past and future of fish consumption: can supplies meet healthy eating recommendations? Mar Pollut Bull 89, 5-11.

18. Naylor RL, Goldburg RJ, Primavera JH et al. (2000) Effect of aquaculture on world fish supplies. Nature 405, 1017-1024.

19. Tyszler M, Kramer G \& Blonk H (2016) Just eating healthier is not enough: studying the environmental impact of different diet scenarios for Dutch women (31-50 years old) by linear programming. Int $J$ Life Cycle Assess 21, 701-709.

20. Reynolds CJ, Buckley JD, Weinstein P et al. (2014) Are the dietary guidelines for meat, fat, fruit and vegetable consumption appropriate for environmental sustainability? A review of the literature. Nutrients 6, 2251-2265.

21. Macdiarmid J (2013) Is a healthy diet an environmentally sustainable diet? Proc Nutr Soc 72, 13-20.

22. Buttriss J \& Riley H (2013) Sustainable diets: harnessing the nutrition agenda. Food Chem 140, 402-407.

23. Riley H \& Buttriss JL (2011) A UK public health perspective: what is a healthy sustainable diet? Nutr Bull 36, 426-431.

24. Food and Agriculture Organization of the United Nations (2016) Food-based dietary guidelines. http://www.fao.org/ nutrition/education/food-dietary-guidelines/home/en/ (accessed November 2016).

25. Health Council of the Netherlands (2011) Guidelines for a Healthy Diet: The Ecological Perspective. The Hague: Health Council of the Netherlands.

26. Nordic Council of Ministers (2012) Nordic Nutrition Recommendations 2012: Integrating Nutrition and Physical Activity. Copenhagen: Nordic Council of Ministers.

27. German Council for Sustainable Development (2013) The Sustainable Shopping Basket: A Guide to Better Shopping. Berlin: German Council for Sustainable Development.

28. Ministry of Health of Brazil (2014) Dietary Guidelines for the Brazilian Population. Brasilia: Ministry of Health of Brazil.

29. Seed B (2015) Sustainability in the Qatar national dietary guidelines, among the first to incorporate sustainability principles. Public Health Nutr 18, 2303-2310.

30. Sustainable Development Commission (2009) Setting the Table: Advice to Government on Priority Elements of Sustainable Diets. London: Department for Environment, Food and Rural Affairs.

31. Martin M, Oliveira F, Dahlgren L et al. (2016) Environmental Implications of Swedish Food Consumption and Dietary Choices. Stockholm: IVL Swedish Environmental Research Institute.

32. Farmery A, Jennings S, Gardner C et al. (2017) Assessing the inclusion of seafood in the sustainable diet literature. Fish Fish 18, 607-618.

33. Ruello A (2011) A Study of The Composition, Value and Utilisation of Imported Seafood in Australia, Project Number 2010/222. Canberra: Fisheries Resource and Development Commission. 
34. National Health and Medical Research Council (2013) Australian Dietary Guidelines: Public Consultation Report. Appendix G: Food, Nutrition and Environmental Sustainability. Canberra: NHMRC.

35. Nicklas TA, Jahns L, Bogle ML et al. (2013) Barriers and facilitators for consumer adherence to the dietary guidelines for Americans: the HEALTH study. J Acad Nutr Diet $\mathbf{1 1 3}$, $1317-1331$

36. Dijkstra SC, Neter JE, van Stralen MM et al. (2015) The role of perceived barriers in explaining socio-economic status differences in adherence to the fruit, vegetable and fish guidelines in older adults: a mediation study. Public Health Nutr 18, 797-808.

37. Ball K, Mishra GD, Thane CW et al. (2004) How well do Australian women comply with dietary guidelines? Public Health Nutr 7, 443-452.

38. Merrigan K, Griffin T, Wilde P et al. (2015) Designing a sustainable diet. Science 350, 165-166.

39. Sacerdote C, Fiorini L, Rosato R et al. (2006) Randomized controlled trial: effect of nutritional counselling in general practice. Int J Epidemiol 35, 409-415.

40. Clonan A \& Holdsworth M (2012) The challenges of eating a healthy and sustainable diet. Am J Clin Nutr 96, 459-460.

41. Burke JD (2012) Bridging the sustainability gap: food systems and the nutrition professional. Nutr Today 47, 155-160.

42. Daly J \& Murray S (2012) Update Australia's dietary guidelines to consider sustainability. http://www.theconversa tion.com/update-australias-dietary-guidelines-to-considersustainability-5439 (accessed September 2017).

43. Crowe T, Forbes-Ewan C, Collins C et al. (2013) New Australian dietary guidelines: experts respond. http://www. theconversation.com/new-australian-dietary-guidelinesexperts-respond-12259 (accessed September 2017)

44. National Heart Foundation of Australia (2013) Healthy Eating and Cholesterol. Healthy Living. Australia: NHFA.

45. van Dooren C \& Aiking H (2016) Defining a nutritionally healthy, environmentally friendly, and culturally acceptable Low Lands Diet. Int J Life Cycle Assess 21, 688-700.

46. Scarborough P, Appleby PN, Mizdrak A et al. (2014) Dietary greenhouse gas emissions of meat-eaters, fish-eaters, vegetarians and vegans in the UK. Clim Change 125 179-192.

47. van Dooren C, Marinussen M, Blonk H et al. (2014) Exploring dietary guidelines based on ecological and nutritional values: a comparison of six dietary patterns. Food Policy 44, 36-46.

48. Weichselbaum E, Coe S, Buttriss J et al. (2013) Fish in the diet: a review. Nutr Bull 38, 128-177.

49. Danenberg N, Remaud H \& Mueller S (2012) Tracking Seafood Consumption and Measuring Consumer Acceptance of Innovation in the Australian Seafood Industry. Project No. 2008/779. Canberra: Fisheries Research and Development Corporation.

50. Fisheries Research and Development Corporation (2013) Australia's top 10 seafood this year. http://www.frdc.com. au/knowledge/news_and_media/media_releases/Pages/ Australia\%E2\%80\%99s-Top-10-Seafood-this-year.aspx (accessed December 2016).

51. Patterson H, Georgeson L, Stobutzki I et al. (2015) Fishery Status Reports 2015. Canberra: Australian Bureau of Agricultural and Resource Economics and Sciences.

52. Flood M, Stobutzki I, Andrews J et al. (2014) Status of Key Australian Fish Stocks Reports 2014. Canberra: Fisheries Research and Development Corporation.

53. Hilborn R, Fulton EA, Green BS et al. (2015) When is a fishery sustainable? Can J Fish Aquat Sci 72, 1433-1441.

54. Pauly D, Watson R \& Alder J (2005) Global trends in world fisheries: impacts on marine ecosystems and food security. Philos Trans R Soc B Biol Sci 360, 5-12.
55. Dietitians Association of Australia (2016) Dietitians Association of Australia 2016 Annual Report. Deakin, ACT: DAA.

56. Stewardson C, Andrews A, Ashby C et al. (2016) Status of Australian Fish Stocks Reports 2016. Canberra: Fisheries Research and Development Corporation.

57. Patterson H, Noriega R, Georgeson L et al. (2016) Fishery Status Reports 2016. Canberra: Australian Bureau of Agricultural and Resource Economics and Sciences.

58. Campbell B \& Hanich Q (2015) Principles and practice for the equitable governance of transboundary natural resources: cross-cutting lessons for marine fisheries management. Marit Stud 14, 8 .

59. Australian Marine Conservation Society (2011) Australia's Sustainable Seafood Guide. http://www.sustainableseafood. org.au (accessed March 2013).

60. Sustainable Table (2016) Switch the Fish Guide. http://www. sustainabletable.org.au/Hungryforinfo/FishyBusiness/tabid/ 143/Default.aspx (accessed December 2016).

61. Pomeroy S \& Worsley A (2008) The relevance of the Heart Foundation of Australia's dietary recommendations for adult Australians: a comparison of views of general practitioners, cardiologists and dietitians. Asia Pac J Clin Nutr 17, 290-296.

62. Gillespie GW (2010) 2009 AFHVS presidential address: The steering question: challenges to achieving food system sustainability. Agric Hum Values 27, 3-12.

63. Jacquet J, Hocevar J, Lai S et al. (2009) Conserving wild fish in a sea of market-based efforts. Oryx 44, 45-56.

64. Davies TD \& Baum JK (2012) Extinction risk and overfishing: reconciling conservation and fisheries perspectives on the status of marine fishes. Sci Rep 2, 561.

65. Fisheries Research and Development Corporation (2015) Australian Standard ${ }^{\circledR}$ AS 5300-2015 Australian Fish Names Standard. Canberra: FRDC.

66. US Department of Agriculture (2017) Americans' seafood consumption below recommendations. http://www.ers. usda.gov/amber-waves/2016/october/americans-seafoodconsumption-below-recommendations/ (accessed March 2017).

67. Nichols P, Virtue P, Mooney B et al. (1998) Seafood the Good Food: The Oil (Fat) Content and Composition of Australian Commercial Fishes, Shellfishes and Crustaceans. FRDC Project no. 95/122. Canberra and Hobart: Fisheries Research and Development Corporation and CSIRO Division of Marine Research.

68. Sissener NH, Waagbø R, Rosenlund G et al. (2016) Reduced $n-3$ long chain fatty acid levels in feed for Atlantic salmon (Salmo salar L.) do not reduce growth, robustness or product quality through an entire full scale commercial production cycle in seawater. Aquaculture 464, 236-245.

69. Zhou S, Smith ADM \& Knudsen EE (2015) Ending overfishing while catching more fish. Fish Fish 16, 716-722.

70. Smithers R (2011) Sales of sustainable seafood soar in UK supermarkets. The Guardian, 17 January. https://www. theguardian.com/environment/2011/jan/17/sustainable-sea food-supermarkets-fish-fight (accessed December 2017).

71. Department of Agriculture (2015) Australia's Seafood Trade. Canberra: Department of Agriculture.

72. Gephart JA, Davis KF, Emery KA et al. (2016) The environmental cost of subsistence: optimizing diets to minimize footprints. Sci Total Environ 553, 120-127.

73. Ereshefsky M (2009) Defining 'health' and 'disease'. Stud Hist Philos Biol Biomed Sci 40, 221-227.

74. Dietary Guidelines Advisory Committee (2015) Scientific Report of the 2015 Dietary Guidelines Advisory Committee: Advisory Report to the Secretary of Health and Human Services and the Secretary of Agriculture. Washington, DC: US Departments of Agriculture and Health and Human Services.

75. Pollen M (2006) Omnivore's Dilemma: A Natural History of Four Meals. New York: Penguin Press. 
76. Nestle M (2002) Food Politics: How the Food Industry Influences Nutrition and Health. Berkeley, CA: University of California Press.

77. Webber CB \& Sarjahani A (2011) Fitting sustainable food systems into dietetic internships - a growing trend. J Hunger Environ Nutr 6, 477-489.
78. Verbeke W, Vanhonacker F, Sioen I et al. (2007) Perceived importance of sustainability and ethics related to fish: a consumer behavior perspective. AMBIO 36, 580-585.

79. Nulty DD (2008) The adequacy of response rates to online and paper surveys: what can be done? Assess Eval High Educ 33, 301-314. 